\title{
Cross-tropopause tracer transport in midlatitude convection
}

\author{
G. L. Mullendore, ${ }^{1}$ D. R. Durran, and J. R. Holton ${ }^{2}$ \\ Department of Atmospheric Sciences, University of Washington, Seattle, Washington, USA \\ Received 25 May 2004; revised 13 December 2004; accepted 14 January 2005; published 25 March 2005.
}

[1] A three-dimensional cloud-resolving model is used to simulate the transport of lowertropospheric passive tracers into the lowermost stratosphere via midlatitude convection. In previous studies of troposphere-to-stratosphere convective transport the extent of irreversible transport is unclear because the tropopause location is difficult to determine in the highly perturbed environment directly above an active storm. To determine the irreversibility of cross-tropopause transport in this study, 10-hour simulations are carried out to cover the growth and decay cycles of the storm. After the decay of convection, isentropes relax to quasi-flat surfaces, and the position of the tropopause becomes much easier to establish. Air parcels containing boundary layer tracers were able to penetrate the stable stratosphere because diabatic processes increased the parcel's potential temperature sufficiently to make the parcel neutrally buoyant at stratospheric altitudes. The boundary layer tracer was carried upward in the core of the updraft whereas tracers originating from higher levels were lifted on the flanks of the updraft and therefore underwent less transport into the stratosphere. Three different cases were simulated: a prototypical supercell, a prototypical multicell, and a supercell observed during the Severe Thunderstorm Electrification and Precipitation Study (STEPS) field campaign. In the prototypical supercell simulation, at $1 \mathrm{~km}$ above the tropopause the maximum concentration of boundary layer tracer is diluted to $26 \%$ of its original concentration; the maximum concentration of the tracer originating in the layer between 1 and $4 \mathrm{~km}$ is diluted to $23 \%$ of its original concentration. Simulation of the STEPS storm showed similar irreversible transport in a less idealized case. Both supercell storms produced more transport than the prototypical multicell storm.

Citation: Mullendore, G. L., D. R. Durran, and J. R. Holton (2005), Cross-tropopause tracer transport in midlatitude convection, J. Geophys. Res., 110, D06113, doi:10.1029/2004JD005059.

\section{Introduction}

[2] The chemical budgets of the upper troposphere and lower stratosphere are strongly influenced by transport of various constituents between the troposphere and stratosphere. Large-scale stratospheric-tropospheric exchange is fairly well understood [Holton et al., 1995], but many aspects of smaller-scale transport are yet to be studied in detail. Convective transport into the lowermost stratosphere, the extratropical stratosphere below the $380-\mathrm{K}$ surface and above the 2-potential vorticity unit surface, is one such area of study.

[3] In the extratropics, air parcels can reach the lowermost stratosphere via three paths: (1) diabatic descent from the stratosphere above $380 \mathrm{~K}$, or overworld; (2) isentropic transport from the lower-latitude troposphere; and (3) upward diabatic transport from the midlatitude troposphere. It

\footnotetext{
${ }^{1}$ Now at Department of Atmospheric and Oceanic Sciences, University of California, Los Angeles, Los Angeles, California, USA.

${ }^{2}$ Deceased 3 March 2004.

Copyright 2005 by the American Geophysical Union. 0148-0227/05/2004JD005059\$09.00
}

has been generally accepted that the majority of air in the lowermost stratosphere is transported via pathways 1 and 2 , as demonstrated by, e.g., Hintsa et al. [1998]. Although convection in midlatitudes may account for only a small percentage of the mass of tropospheric air mixed into the lowermost stratosphere, deep convection is a particularly effective method for transporting boundary layer air to the altitude of the upper troposphere/lower stratosphere where the chemical impact can be significant because boundary layer air has a much different chemical composition than the free troposphere. Also, convection can transport air from the surface to the stratospheric altitudes on the order of an hour, thereby preserving the concentrations of short-lived chemical constituents, while synoptic-scale disturbances such as extratropical cyclones would require days to accomplish the same mixing [Sigmond et al., 2000], and turbulent diffusive processes would require months [Dickerson, 1987].

[4] Sprenger and Wernli [2003] detailed the source and destination regions for deep troposphere-to-stratosphere transport in the Northern Hemisphere extratropics. They found that deep exchange events (parcel origin below $700 \mathrm{hPa}$ ) accounted for a maximum of $25 \%$ of analyzed troposphere-to-stratosphere transport events. These events 
originated primarily in the oceanic storm tracks and were associated with the "warm conveyor belts" found in midlatitude cyclones. Using the European Centre for MediumRange Weather Forecasts (ECMWF) reanalysis data, however, limited the scales of motion considered in their study because the resolution of the input data was 6 hours in time and $1^{\circ}$ in space. Hegglin et al. [2004] measured increased tropospheric trace gas mixing ratios in the stratosphere during a flight of the Spurenstofftransport in der Tropopausenregion (SPURT) campaign. Their analysis demonstrated that the observed feature was most likely a result of nearby strong convection, providing strong experimental evidence that intense midlatitude convection can influence the chemical makeup of the lowermost stratosphere. Furthermore, they computed forward trajectories showing that $97 \%$ of the tropospheric air parcels that crossed the tropopause remained in the stratosphere.

[5] Other observational studies have examined the convective environment directly. Poulida et al. [1996] reported findings from measurements taken of a squall line and mesoscale convective complex (MCC) over North Dakota. Aircraft flights through this storm encountered low-ozone/ high-carbon monoxide air above air that had ozone concentrations indicative of stratospheric air, suggesting that a lens of tropospheric air had been injected into the stratosphere. The eventual fate of the tropospheric lens was uncertain, however. The flight measurements were taken while convection was still active, allowing for the possibility that the tropopause was distorted because of the storm. Strom et al. [1999] reported in situ measurements performed in two cumulonimbus anvils over western Europe and observed that much of the air in the anvil was rapidly transported from the boundary layer and experienced little dilution. This study used potential vorticity surfaces, calculated from ECMWF meteorological fields, to define the tropopause region and concluded that some boundary layer air was transported into the lowermost stratosphere.

[6] Model studies of the transport of tracers in convection have proved difficult because many parameters affect storm evolution and hence transport, including physical parameterizations, numerical schemes and related computational parameters, and initial and boundary conditions [Park and Droegemeier, 2000]. In the few modeling studies that have included analysis of cross-tropopause transport due to deep convection [e.g., Stenchikov et al., 1996; Skamarock et al., 2000] the tropopause is often defined by a single altitude or pressure level, which may not accurately describe a stormperturbed tropopause. Stenchikov et al. [1996] used a twodimensional model to simulate a deep midlatitude convective event. The simulated storm injected boundary layer tracers above the prestorm tropopause level and brought ozone down from the stratosphere. The authors extrapolated the findings to estimate the cross-tropopause exchange due to all mesoscale convective systems, concluding that the upward flux of water vapor and other boundary layer tracers could be locally significant. However, because the tropopause itself was pushed upward by the strong updrafts, the degree of permanent transport into the lower stratosphere was unclear. Stenchikov et al.'s [1996] study also had relatively low numerical resolution in the upper troposphere and lower stratosphere. Stenchikov et al. [1996, p. 6850] acknowledged that "long-term net transport remains highly uncertain."
Wang [2003] simulated a deep supercell storm and showed a water vapor plume above the main cloud anvil, attributing the plume to gravity wave breaking at cloud top which caused mixing of water vapor from the overshooting dome with stratospheric air. Wang [2003] used a $\Theta_{e}$ surface to define the tropopause location because the surface roughly coincided with the cloud top. The simulation was terminated at $150 \mathrm{~min}$, making the long-term evolution of the water vapor plume uncertain, as acknowledged by the author.

[7] In this study, we attempt to more accurately characterize troposphere-to-stratosphere transport of passive tracers due to isolated midlatitude convection. We address many of the sources of uncertainty in previous studies by using a three-dimensional numerical model to assess the amount of air injected above a time-evolving tropopause (as opposed to a flat surface) and to track the long-term evolution of the injected air parcels. In section 2 we introduce the model and discuss some of the model initialization issues. In section 3 we present the results from an idealized supercell storm and use this case to investigate the main features of tracer transport throughout the depth of the model. In section 4 we contrast the troposphere-stratosphere exchange produced by an idealized multicell storm with that generated by the supercell storm. In section 5 we describe the transport produced in a simulation of a remarkably deep convective event observed in the 2000 Severe Thunderstorm Electrification and Precipitation Study (STEPS) campaign. Section 6 summarizes the implications of these results for the transport of selected chemical species. Section 7 contains the conclusions.

\section{Model Description}

\subsection{Numerics}

[8] The model used is a three-dimensional, cloudresolving mesoscale model based on that of Piani et al. [2000]. The version used here includes passive tracer advection. Previous model versions used a leapfrog scheme for scalar advection, which is a satisfactory scheme for advection of smooth variables but a scheme which tends to cause serious overshoots and undershoots in the vicinity of strong gradients. The addition of a flux-limited advection scheme [LeVeque, 1996] for scalar advection was a crucial improvement allowing for the more realistic advection of sharp gradients in the tracer fields. A latitude of $37^{\circ}$ was assumed; $f$ was set to $8.57 \times 10^{-5} \mathrm{~s}^{-1}$ for the $f$ plane approximation. Storms were initialized with a warm bubble that increased in temperature gradually over $5 \mathrm{~min}$ to a maximum of $2 \mathrm{~K}$. The microphysical parameterization is a six-water category scheme tuned for midlatitude storms (see Tao and Simpson [1993] for details).

[9] Although we are interested in the long-term evolution of the tracer plume, the processes we are simulating are still faster than the radiative timescale of 12 hours. We therefore neglect radiation in the simulations to save computational expense. The longer-term ( $>12$ hours) mixing of the chemical plume could be affected by radiative fluxes associated with enhanced water vapor in the plume (the anvil cloud disappears by 5 hours) and will be addressed in future work.

[10] Turbulent mixing is parameterized by a first-order closure formulation which depends on the ratio of the magnitudes of stratification to shear [Durran and Klemp, 


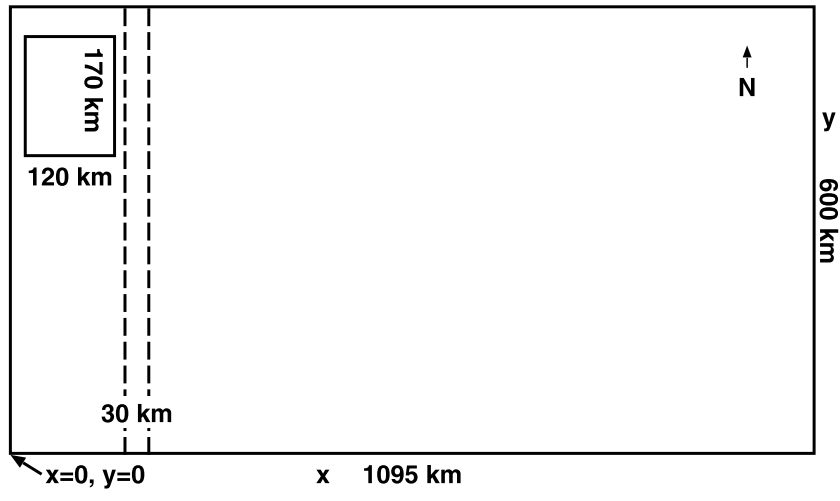

Figure 1. Inner and outer grids used for storm simulations. The transition zone between the moist boundary layer (west) and the dry boundary layer (east) is shown by the dashed lines.

1983]. The subgrid-scale mixing terms are proportional to both the shear deformation and mixing coefficient and "turn on" for Richardson number $<1$ for these model runs. Here the Richardson number is defined as $R i=N / \beta$, where $N$ is the buoyancy frequency and $\beta$ represents the shear deformation. The mixing coefficient, $K_{m}$, is proportional to the grid spacing of the resolution on the finest grid, the shear deformation, and the Richardson number:

$$
K_{m}=(0.21)^{2} \Delta x \Delta z \beta^{1 / 2} \max (1-R i, 0)^{1 / 2} .
$$

[11] To assess the sensitivity of the cross-tropopause mixing to the mixing parameterization, we set $K_{m}$ proportional to $(\Delta z)^{2}$ instead of $\Delta z \Delta x$, thereby decreasing the mixing coefficient by one fourth in the test case. (The mixing coefficient for the control case assumes the largest turbulent eddies proportional to the size of the grid box in the finest grid, $\Delta z \Delta x$, where $\Delta z=250 \mathrm{~m}$ and $\Delta x=1000 \mathrm{~m}$.) The maximum vertical velocity is similar for both cases, although the amount of mixing is stronger in the control case. The case with reduced $K_{m}$ produced more transport throughout the simulation. At 4 hours the amount of boundary layer material transported to the stratosphere in the case with reduced $K_{m}$ was $11 \%$ higher than in the control case. Although a higher mixing coefficient (control case) increases the mixing at cloud top which increases the turbulent transport across the tropopause, stronger mixing in the updraft dilutes both the tracer concentrations and the buoyancy of the updraft and thereby reduces the transport of lower-tropospheric tracers up to the tropopause level. The control case appears to represent a lower bound, in the mixing coefficient parameter space, for transport into the stratosphere. The mixing coefficient was set as in the control case for cases presented in this study.

\subsection{Storm Dissipation and Nesting}

[12] A major obstacle to simulating the storm evolution over a 10-hour period is the tendency for the continual generation of new convective cells. This occurs as the storm outflow, the cold pool, advances into the unperturbed model domain. If the initial storm environment is horizontally homogeneous and the inflow conditions remain fixed at the lateral boundaries, any unperturbed regions within the numerical domain have the same convective available potential energy to promote new cell growth as the region in which the first cell formed. As a result, new cells are episodically generated, making it difficult to assess the net cross-tropopause transport that remains after the primary storm dissipates. In addition, the new cells may eventually reach the domain boundaries and set off numerical instabilities. To avoid these difficulties, we added an area of dry air in the initial domain. Drying the boundary layer reduces the available potential energy, thus suppressing the growth of new cells. The interface between the two air masses is a straight line transition zone (Figure 1, dashed lines), $30 \mathrm{~km}$ wide, in which the water vapor mixing ratio decreases linearly with $x$ throughout the depth of the dry zone. The dry zone is $1.9 \mathrm{~km}$ deep for the idealized cases and $5 \mathrm{~km}$ for the STEPS case. Throughout that depth the water vapor mixing ratio is decreased across the transition zone by a set percentage $(50 \%$ for the idealized cases and $75 \%$ for the STEPS case). The main updraft reaches the dry air mass $\sim 1.5$ hours after model initialization in all simulations, giving the storms sufficient time to mature while keeping storm lifetimes similar, allowing us to compare the transport magnitudes of different simulations.

[13] Grid nesting was used in order to reduce the computational expense of the model runs while having a large enough domain to capture the long-term evolution of the tracer plume. The inner grid, which contained all of the deep updrafts, had a horizontal resolution of $1 \mathrm{~km}$, a vertical resolution of $250 \mathrm{~m}$, and a 3-s time step. The outer grid had a horizontal resolution of $3 \mathrm{~km}$, a vertical resolution of $250 \mathrm{~m}$, and a 9-s time step. Figure 1 shows the configuration of the inner and outer domains. Both grids had a depth of $20 \mathrm{~km}$.

\subsection{Tracer Initialization}

[14] The major goal of this work is to quantify the mass transport from the lower troposphere to the upper troposphere and lower stratosphere produced by extratropical convective storms. For this purpose it is convenient, following the work of Scala et al. [1990] and Lu et al. [2000], to track the evolution of passive tracers that are initially confined within horizontally homogeneous layers. Wang and Chang [1993] included chemistry in their simulations of chemical transport but found that dynamical processes accounted for nearly $100 \%$ of the in-cloud variation for insoluble gases that had chemical lifetimes longer than the storm itself (e.g., ozone), demonstrating that chemistry could be neglected for such gases.

[15] Each tracer is initialized with a mixing ratio of unity throughout its "source" layer and zero outside that layer. Five tracers are initially confined in layers from 0.1 to $1.4 \mathrm{~km}, 1.4$ to $4.4 \mathrm{~km}, 4.4$ to $7.4 \mathrm{~km}, 7.4 \mathrm{~km}$ to tropopause, and tropopause to top of domain (Figure 2). Starting at the domain top, these tracers will be referred to as TR1 (stratosphere) to TR5 (surface). In each layer the tracer concentration transitions from 0 to $1 \mathrm{~kg} \mathrm{~kg}^{-1}$ over one vertical grid interval, $250 \mathrm{~m}$. Each tracer layer encompasses a minimum of five vertical grid steps.

\section{Idealized Supercell Storm}

\subsection{Initialization}

[16] The supercell storm was created using idealized thermodynamic and wind profiles [Weisman and Klemp, 


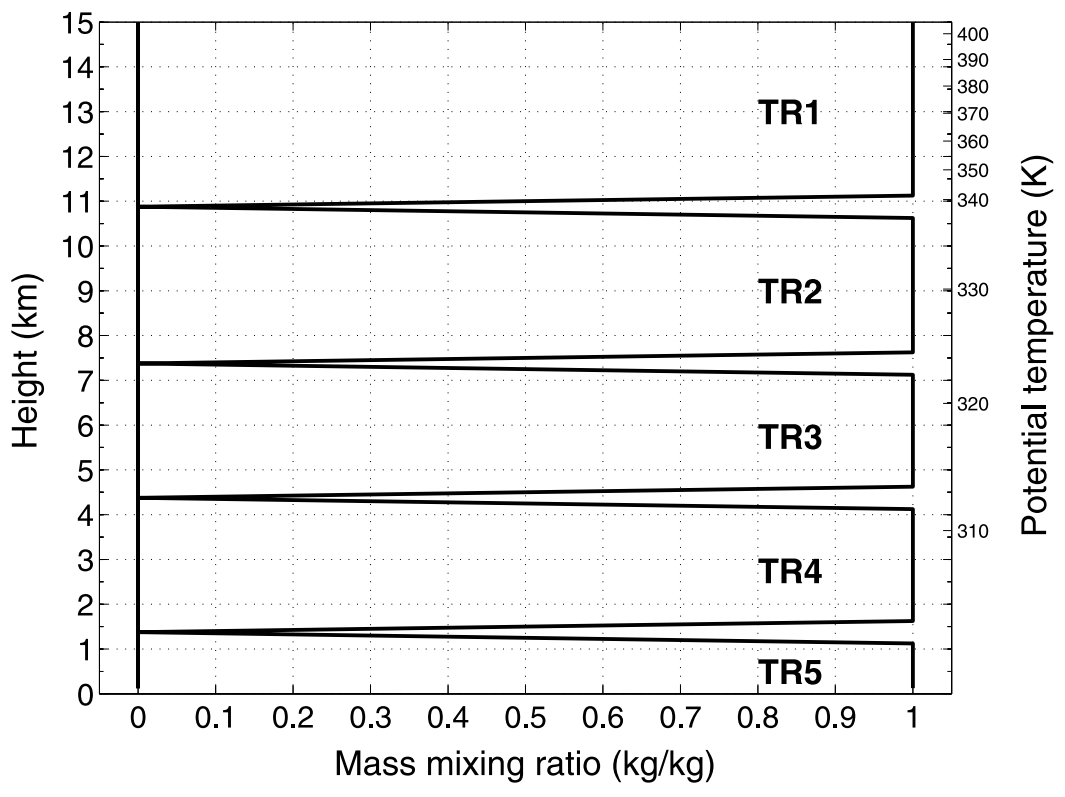

Figure 2. Vertical profiles showing the initial mixing ratios for the passive tracers. TR5 serves as a proxy for a tracer with a boundary layer source. TR1 serves as a proxy for a tracer with a stratospheric source.

1986]. The storm type was determined according to the value of the bulk Richardson number $(\mathrm{BRN})$, a ratio of convective available potential energy (CAPE) over lowlevel wind shear. Weisman and Klemp [1982] showed the $\mathrm{BRN}$ range for supercells to be $10-50$. The supercell case has a BRN of 35 . Figure 3 a shows the thermodynamic profile, and Figure $3 \mathrm{~b}$ (solid line) shows the wind profile. This environment has a CAPE of $2500 \mathrm{~J} \mathrm{~kg}^{-1}$ and zero wind shear above $5 \mathrm{~km}$. In order to follow the motion of the storm itself the computational domain translates at a speed of $11.1 \mathrm{~ms}^{-1}$ in the $x$ direction and $6.4 \mathrm{~ms}^{-1}$ in the $y$ direction. The original sounding was found to be dynamically unstable in the layer below $5 \mathrm{~km}$ because of areas of low-level vertical wind shear (Richardson number near 0.25 ) triggering subgrid-scale mixing. In order to avoid this problem we allowed the instability to modify the sounding through mixing in the absence of convection. Once the mixing had stabilized the environment, a modified initial sounding was created. This stabilization process had minimal effect on the overall storm environment; CAPE was changed by only $4 \%$. The modified sounding remained in the same storm regime and allowed us to avoid vertical smearing of the lowest tracer levels.

\subsection{Simulation Overview}

[17] A single updraft cell is present $30 \mathrm{~min}$ into the simulation, which reaches a height of $13.8 \mathrm{~km}$ with maximum vertical velocity of $41 \mathrm{~ms}^{-1}$ at $9.5 \mathrm{~km}$. The initial cell has a radius of $5 \mathrm{~km}$, which is the approximate radius of the subsequent updrafts in the supercell case. The downdrafts that flank this main cell are much weaker than the updrafts, with a maximum downward velocity of $8 \mathrm{~ms}^{-1}$. At midlevels $(3-7 \mathrm{~km})$ the main downdraft lies downwind of the updraft and is associated with the evaporation of falling hydrometeors. From 8 to $12 \mathrm{~km}$ the downdraft maximum is upwind from the updraft, created by a combination of diabatic cooling due to evaporation caused by the entrain- ment of dry air into the cloud and subsidence caused by dynamical adjustment to the upward flux of air. Above $12 \mathrm{~km}$ the downward air motions are due to gravity waves generated by the overshooting convective tower.

[18] The updraft strength surpasses $50 \mathrm{~ms}^{-1}$ by $45 \mathrm{~min}$ and remains this strong until 2 hours into the simulation. This persistent strong vertical velocity is a signature of a supercell storm [Weisman and Klemp, 1986]. The eastern edge of the storm reaches the dry region at $\sim 1.5$ hours, and the storm begins to dissipate at this time. At the time the dry air mass is encountered the vertical velocity at $9.5-10.5 \mathrm{~km}$ has reached a storm maximum of $60 \mathrm{~ms}^{-1}$. The updraft reaches a maximum height of $14.3 \mathrm{~km}$.

\subsection{Tracer Transport}

[19] Figure 4 shows snapshots of an isosurface of the boundary layer tracer, TR5, with a concentration of $0.1 \mathrm{~kg} \mathrm{~kg}^{-1}$ (i.e., $10 \%$ of its initial boundary layer value). The tracer is pulled up in the deep updrafts and is deposited near the level of neutral buoyancy (LNB). Although tracerrich air reaches the highest altitudes in overshooting tops $(14 \mathrm{~km})$, that air subsequently descends without irreversibly depositing significant tracer mass in the stratosphere.

[20] The lofted air may remain in the stratosphere via one, or both, of the following two processes: (1) Enough latent heating occurs to make the lofted air neutrally buoyant at its new altitude or (2) the lofted air undergoes turbulent mixing at cloud top, which raises the parcel's temperature enough to be neutrally buoyant in the stratosphere. Figure 5 shows vertical slices through the TR5 tracer plume at 2 hours (Figure 5a) and 10 hours (Figure 5b). The color contours of TR5 show concentrations from 0.05 to $1 \mathrm{~kg} \mathrm{~kg}^{-1}$, with an interval of $0.05 \mathrm{~kg} \mathrm{~kg}^{-1}$. The thick black line represents the tropopause defined as the isosurface of $d \Theta / d z=$ $0.00935 \mathrm{~K} \mathrm{~m}^{-1}$, which we found to be the best measurement of the location of the evolving tropopause. At 2 hours the tropopause is highly deformed, and the tracer plume 

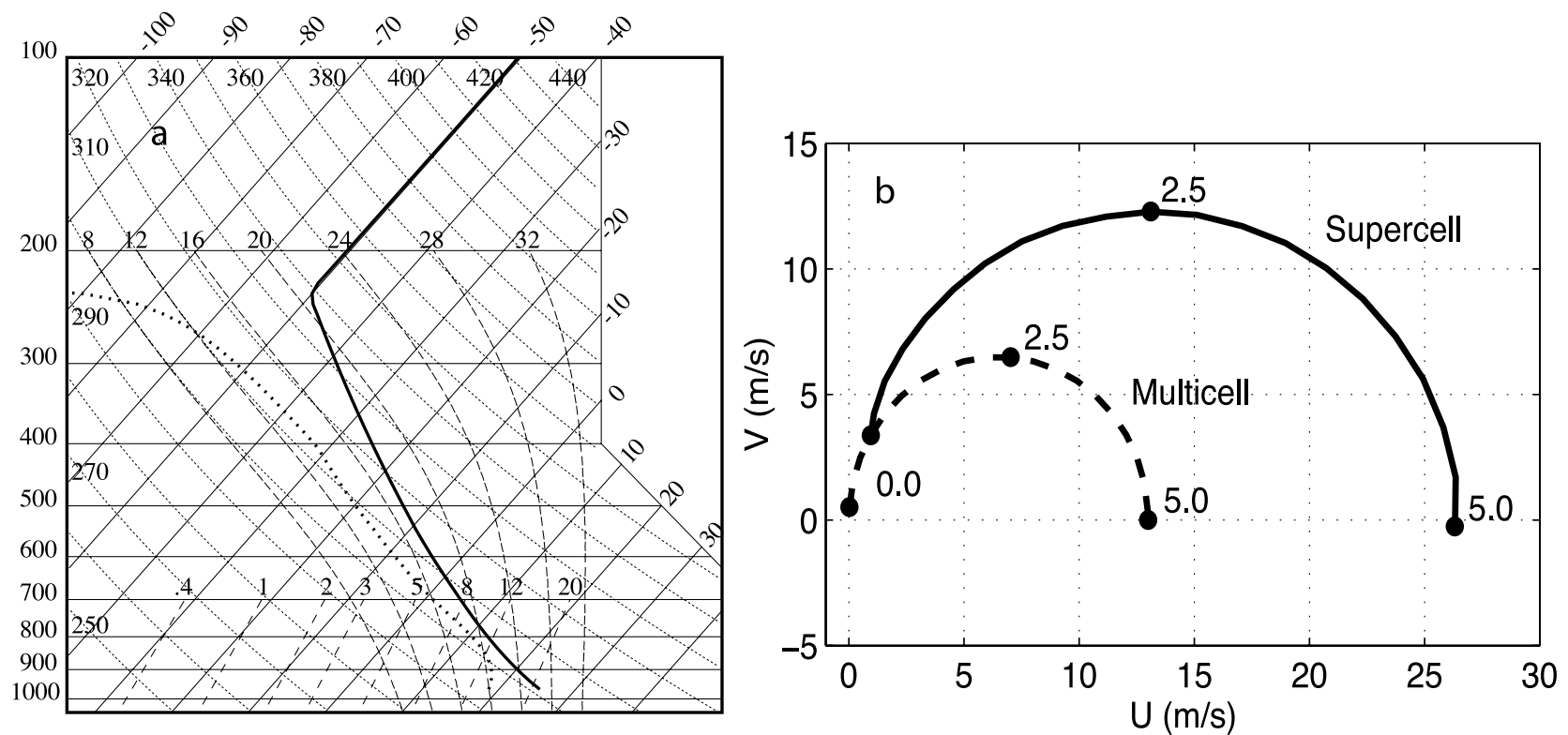

Figure 3. Initialization values for the idealized supercell and multicell simulations. (a) Skew-T plot showing temperature (solid line) and dew point temperature (dotted line) for both simulations. This profile has a convective available potential energy of $2500 \mathrm{~J} \mathrm{~kg}^{-1}$. (b) Hodograph showing the low-level wind shear for the supercell (solid line) and multicell (dashed line) simulations. Numbers at points on line give altitude in kilometers. Neither case has wind shear above $5 \mathrm{~km}$.

extends above $13 \mathrm{~km}$, but by 10 hours the tropopause has become quasi-planar with no significant tracer concentrations above $13 \mathrm{~km}$. Significant tracer still exists above the tropopause, however, so irreversible transport has occurred. The steep tracer gradients resemble observations of steep chemical gradients of stratospheric air masses influenced by deep convection [e.g., Hegglin et al., 2004].

[21] The vertical gradient of $\Theta$ is the best tropopause definition for this study because the $d \Theta / d z$ surface relaxes to a quasi-planar surface after several hours unlike other possible tropopause definitions, such as potential vorticity. It seems likely that air that has been carried through the stability boundary of the strong $d \Theta / d z$ gradient will remain lofted long enough that mesoscale mixing processes such as gravity wave breaking can mix the tropospheric and stratospheric chemicals together. Such stratospheric mixing processes are not included in this mesoscale simulation, but a rough estimate of 3 days for mixing time can be calculated following Haynes [2002]. Note that $\Theta$ surfaces also become quasi-planar after several hours, but unlike high stability values, high $\Theta$ values do not necessarily represent parcels that have inhibited vertical mixing.

[22] Figure 6 shows the total amount of each tracer present in the stratospheric portion of the computational domain as a function of time. The supercell storm transports $18.3 \times 10^{11} \mathrm{~kg}$ of TR5 and $13.9 \times 10^{11} \mathrm{~kg}$ of TR4 into the stratosphere. Figure 6 (solid lines) shows the total mass calculated by finding the areas of the model domain in which $d \Theta / d z$ exceeded a stratospheric threshold value of $0.00935 \mathrm{~K} \mathrm{~m}^{-1}$ and summing the mass of the tracer in those areas. Figure 6 (dashed lines) shows transport calculated by summing all the tracer mass above the altitude of the initial unperturbed tropopause. For the lowest-level tracers, TR5 and TR4, one can see the signature of the air parcels pushed beyond their LNB from 0 to 4 hours (Figure 6) in that the amount of tracer above the initial tropopause altitude exceeds the amount above the stability tropopause. Although parcels have crossed a given height, they have not crossed the tropopause stability boundary. After $\sim 4$ hours the amount above the stability boundary exceeds the amount above the initial altitude tropopause. Although the stability boundary has relaxed to quasi-planar by this time, its average height is below its original height because of small-amplitude gravity waves with large horizontal wavelengths caused by the anvil-sized mass displacement at the tropopause.

[23] TR5 has the highest mass flux of all the tracers into the stratosphere because TR5 is at the core of the updraft and is therefore isolated from the entrainment that occurs in the turbulent mixing along the updraft flanks. Figure 7 shows profiles through the updrafts at 1.5 hours along the line $y=456 \mathrm{~km}$ at altitudes of $2.6,5.6,8.6$, and $11.6 \mathrm{~km}$; the lines represent the TR5 (black solid lines) and TR4 (black dashed lines) concentrations and the vertical velocity (gray lines). At $2.6 \mathrm{~km}$ a peak in the TR5 and a hole in the TR4 concentrations are approximately coincident with the core of the updraft. Above the TR4 layer the contours clearly show that the peak values in TR5 coincide with the strongest updraft location while the peak TR4 concentrations are offset, consistent with the TR4 tracer being pulled up on the flanks of the updraft rather than in the core.

[24] Figure 8 shows the mass distribution as a function of altitude for each tracer. The original boundaries between tracer layers are shown by the gray lines. Figure 8a shows the horizontally integrated mass at each level at 10 hours, which is dominated by nonconvective transport (diffusion and large-scale subsidence). In Figure $8 \mathrm{~b}$ we emphasize the convective transport by plotting the lines from Figure 8a 

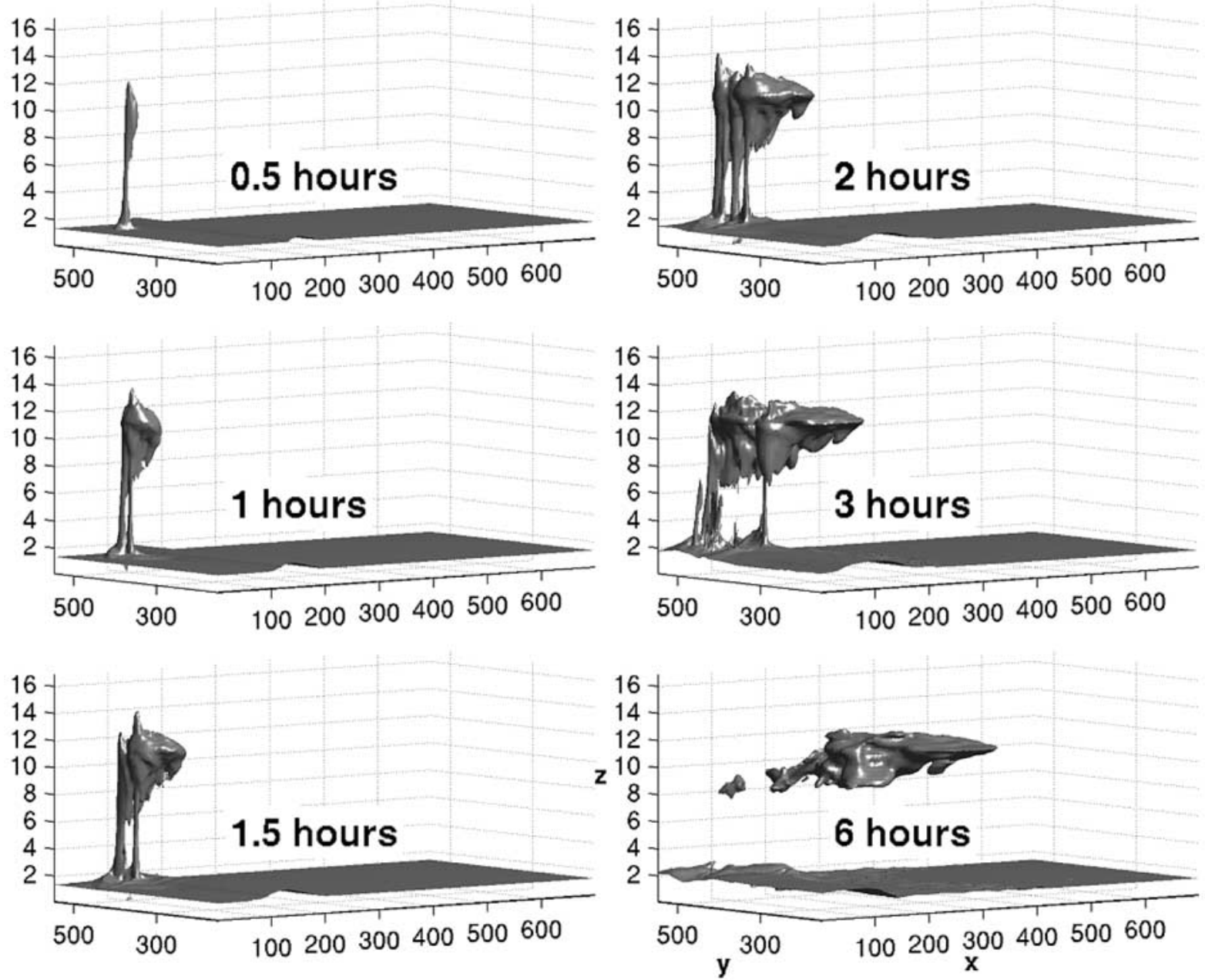

Figure 4. Isosurface of TR $5=0.1 \mathrm{~kg} \mathrm{~kg}^{-1}$ at $0.5,1,1.5,2,3$, and 6 hours into the supercell simulation. The portion of the model domain shown is $x=0$ to $700 \mathrm{~km}, y=150$ to $550 \mathrm{~km}$, and $z=0$ to $17 \mathrm{~km}$.

only at altitudes outside those affected by the nonconvective transport, which, for the purposes of this computation, is taken as the region at least $1.5 \mathrm{~km}$ above or below the initial location of each tracer. For example, the initial region for TR3 is $4.4-7.4 \mathrm{~km}$, and the final profile for TR3 is plotted from the surface to $2.9 \mathrm{~km}$ and from $8.9 \mathrm{~km}$ to the domain top in Figure $8 b$.

[25] In Figure 8b, TR3, TR4, and TR5 all show a bimodal structure in the upper troposphere/lower stratosphere, with a local minimum at $\sim 10 \mathrm{~km}$, which is just below the tropopause $(10.9 \mathrm{~km})$. The maximum at $11.2 \mathrm{~km}$ is due to the convective outflow near the LNB, which is the primary outflow level for the first 3 hours of simulation. This outflow corresponds to the transport due to the storm cells that matured before encountering the dry air mass and demonstrates the importance of latent heating in mass transport. The tracer mass at this altitude continues to increase until 5 hours, although the deposition rate decreases sharply after 3 hours. After 5 hours the mass at $11.2 \mathrm{~km}$ decreases somewhat because of subsidence and diffusion, but the amount of mass does not decrease below the amount of mass at 3 hours. The lower maximum is less well defined for TR5 but shows up clearly in TR4. Hourly plots of vertical profile of domain-integrated TR4 (not shown) show the lower peak outflow level decreasing from $9 \mathrm{~km}$ at 2 hours to $8.5 \mathrm{~km}$ at 6 hours. The lower peak does not appear in the domain-integrated tracer plots until 2 hours and has reached its peak value by 6 hours. Back trajectory analysis from the 9-km level shows that this air primarily originated around $2.5 \mathrm{~km}$ in the TR4 layer and was transported upward by relatively weak updraft cells occurring after the original storm had dissipated.

[26] It is clear from Figure $8 \mathrm{~b}$ that while all the tropospheric tracers have experienced some mass transport into the stratosphere, the most transport occurs for TR5 and TR4. Also evident from Figure $8 \mathrm{~b}$ is the significant amount of mass deposited above the LNB $(11.4 \mathrm{~km})$. The LNB is defined as the maximum LNB for near-surface parcels $(z \leq$ $600 \mathrm{~m}$ ) at initialization (the LNB decreases above $600 \mathrm{~m}$ ). Air parcels that remain above the LNB have entrained higher- $\Theta$ air from above (from the stratosphere) to increase their temperatures beyond that reachable from latent heating alone, demonstrating the importance of turbulent mixing.

[27] Figure 9 shows parcel heating along a trajectory in an updraft core and along another trajectory on an updraft flank. A point is plotted every $72 \mathrm{~s}$ along the parcel path; the point color indicates the magnitude (from -5 to $5 \mathrm{~K}$ ) of heating in that 72-s period. The latent heating (Figures 9a 

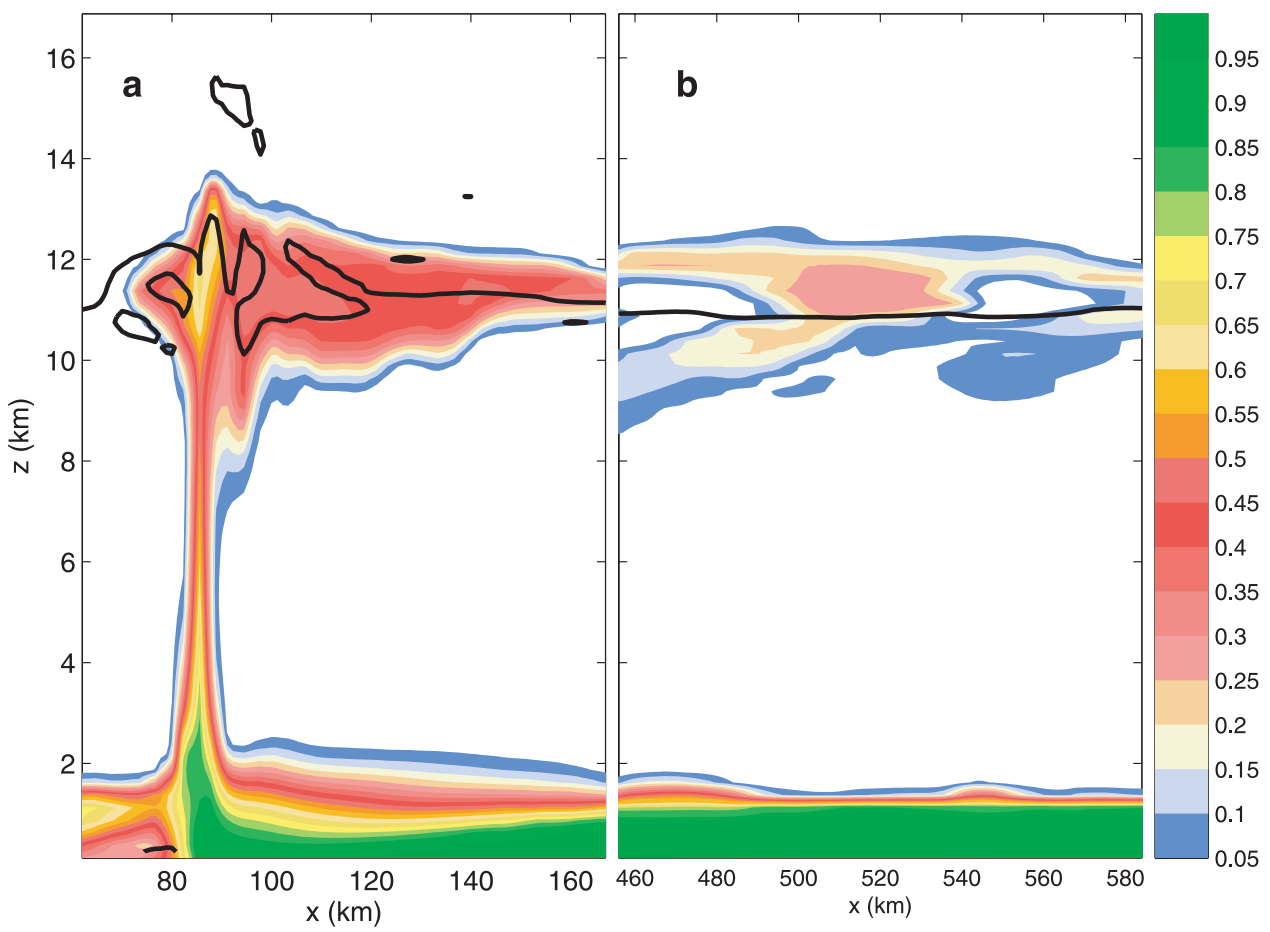

Figure 5. Vertical cross section through supercell anvil at (a) 2 hours and (b) 10 hours. The colored contours show the concentration of tracer TR5. The thick black line shows the location of the $d \Theta / d z=$ 0.00935 isosurface.

and 9d) was output from the model microphysical scheme directly. Temperature change due to mixing (Figures 9b, 9c, and $9 \mathrm{e}$ ) is the residual value after subtracting the latent heating amount from the local change in $\Theta$, which includes numerical diffusion as well as mixing. The total change along each trajectory is also indicated for potential temperature $(\Delta \Theta)$, latent heating $(\Delta \mathrm{LH})$, and mixing $(\Delta \mathrm{MX})$. The total potential temperature change is dominated by latent heating along both trajectories, but in the flank trajectory, where the parcels are less protected, the mixing plays a larger role, accounting for $32 \%$ of the change in $\Theta$, compared with $10 \%$ in the core.

[28] Although an order of magnitude smaller than the mixing in the updraft cores and overshooting tops, the trajectories show that mixing processes are active throughout the anvil region of the cloud. Figure 9c shows the same parcel trajectory as in Figure 9b but with the color magnitudes reset to -0.5 to $0.5 \mathrm{~K}$. In a finer-scale model, Lane et al. [2003] also showed turbulent mixing throughout the cloud. This mixing increases the opportunities for tropospheric air to reach a potential temperature that will allow the air to remain in the stratosphere.

\section{Idealized Multicell Storm}

[29] It is well known that vertical variations in CAPE and lower-tropospheric wind shear regulate the basic organization of long-lived deep convective storms into two prototypical cases: supercellular and multicellular [Weisman and Klemp, 1982]. The effects of different storm morphology on troposphere-stratosphere exchange were tested by reducing the low-level wind shear in the idealized supercell case by a factor of one half to create an environment favorable for a multicell storm (see Figure 3). Since both storms have identical thermodynamic structure, they have the same CAPE and the same level of neutral buoyancy. The weaker shear raises the bulk Richardson number to 115 , putting the storm in the multicell regime [Weisman and Klemp, 1982]. Like the supercell case, there is no environmental wind shear above $5 \mathrm{~km}$.

[30] The updraft strength reaches $50 \mathrm{~ms}^{-1}$ by $30 \mathrm{~min}$ but subsequently decreases in magnitude and does not surpass

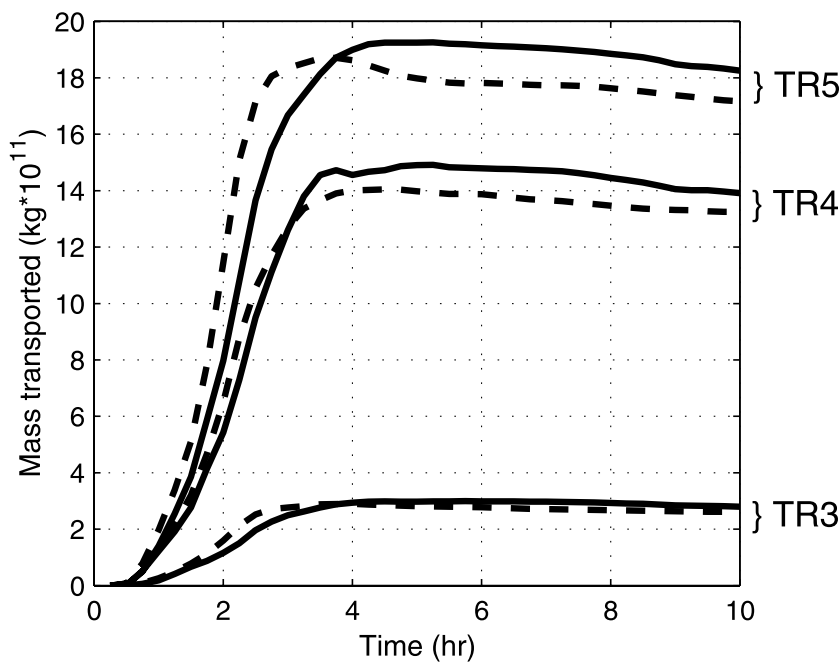

Figure 6. Total amount of tracer transported into the stratosphere. Solid lines show total transport using $d \Theta / d z$ as the tropopause definition; dashed lines show total transport above a constant altitude. The tracer associated with each pair of lines is labeled on the right. 


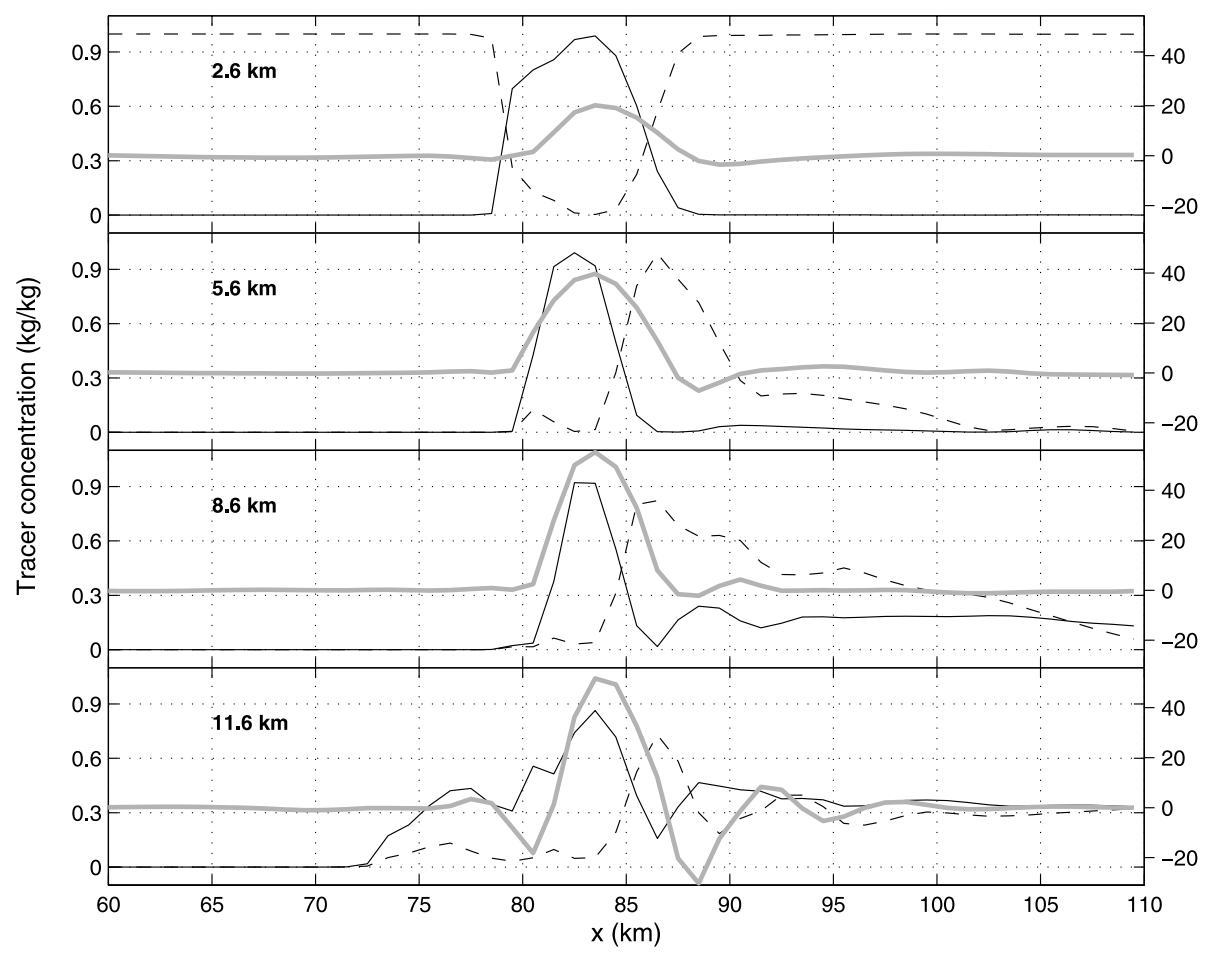

Figure 7. Profiles through the supercell updraft at 1.5 hours at $y=456 \mathrm{~km}$ and the altitudes $2.6,5.6,8.6$, and $11.6 \mathrm{~km}$. The thin black lines show the concentrations of TR5 (solid) and TR4 (dashed). Vertical velocity is shown as a thick gray line.

$50 \mathrm{~ms}^{-1}$ again until 1.25 hours. The individual cells in the multicell storm had an average lifetime of $45 \mathrm{~min}$. The cells had radii of 3-4 km, smaller than the cells in the supercell case. At 1.5 hours the updraft at $10.5 \mathrm{~km}$ has reached the storm maximum value of $57 \mathrm{~ms}^{-1}$. The updraft extends to a height of $13.8 \mathrm{~km}$.

[31] Figure 10 shows the horizontally integrated mass redistribution due to convective transport in the multicell storm in the same form as that for the supercell case in Figure $8 \mathrm{~b}$. Both storms produce generally similar transports, although in the multicell case, there is less transport into the stratosphere and more transport into the upper troposphere. The bimodal structure evident in the supercell storm mixing ratio plot is more pronounced in the multicell case, with maxima at $z=8.5$ and $11 \mathrm{~km}$, because more weak cells are present after the multicell storm encounters the dry low-
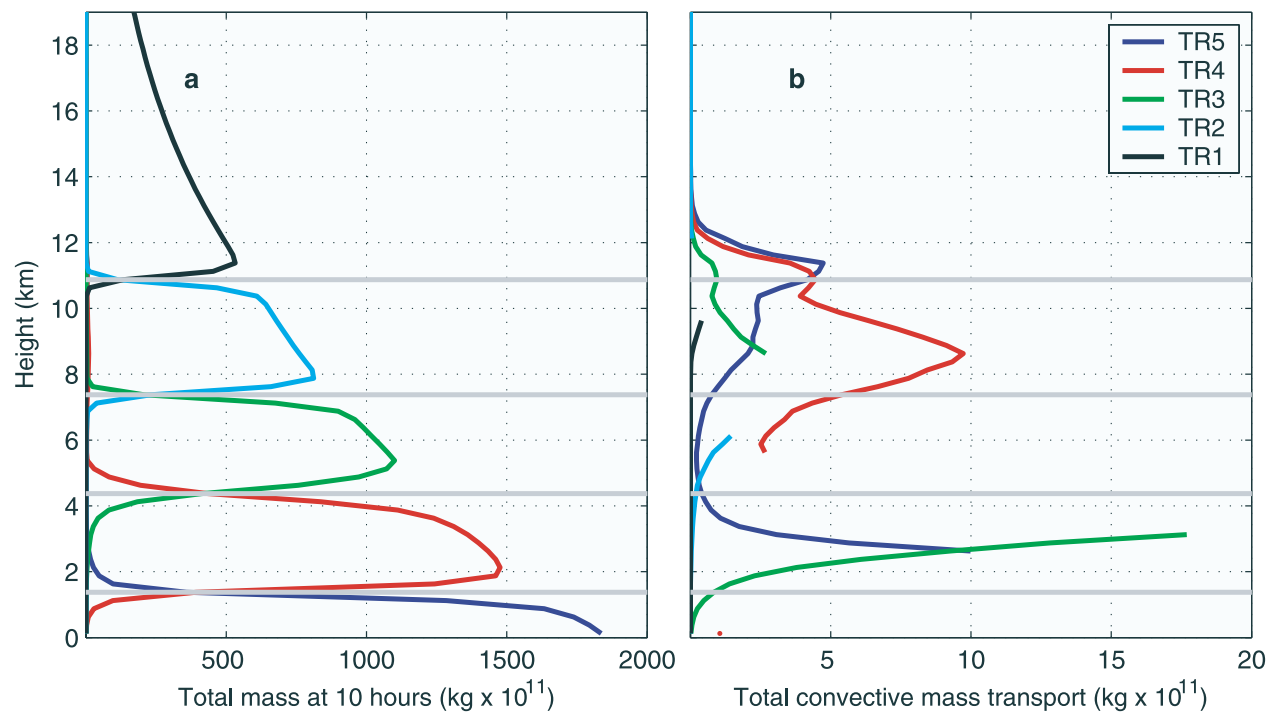

Figure 8. Tracer mass redistribution as a function of altitude. TR5 is shown in blue, TR4 is shown in red, TR3 is shown in green, TR2 is shown in cyan, and TR1 is shown in black. (a) Horizontally integrated mass of each tracer at 10 hours. (b) Convective mass redistribution at 10 hours (see text for details). The gray lines indicate the original locations of the tracer layers. 


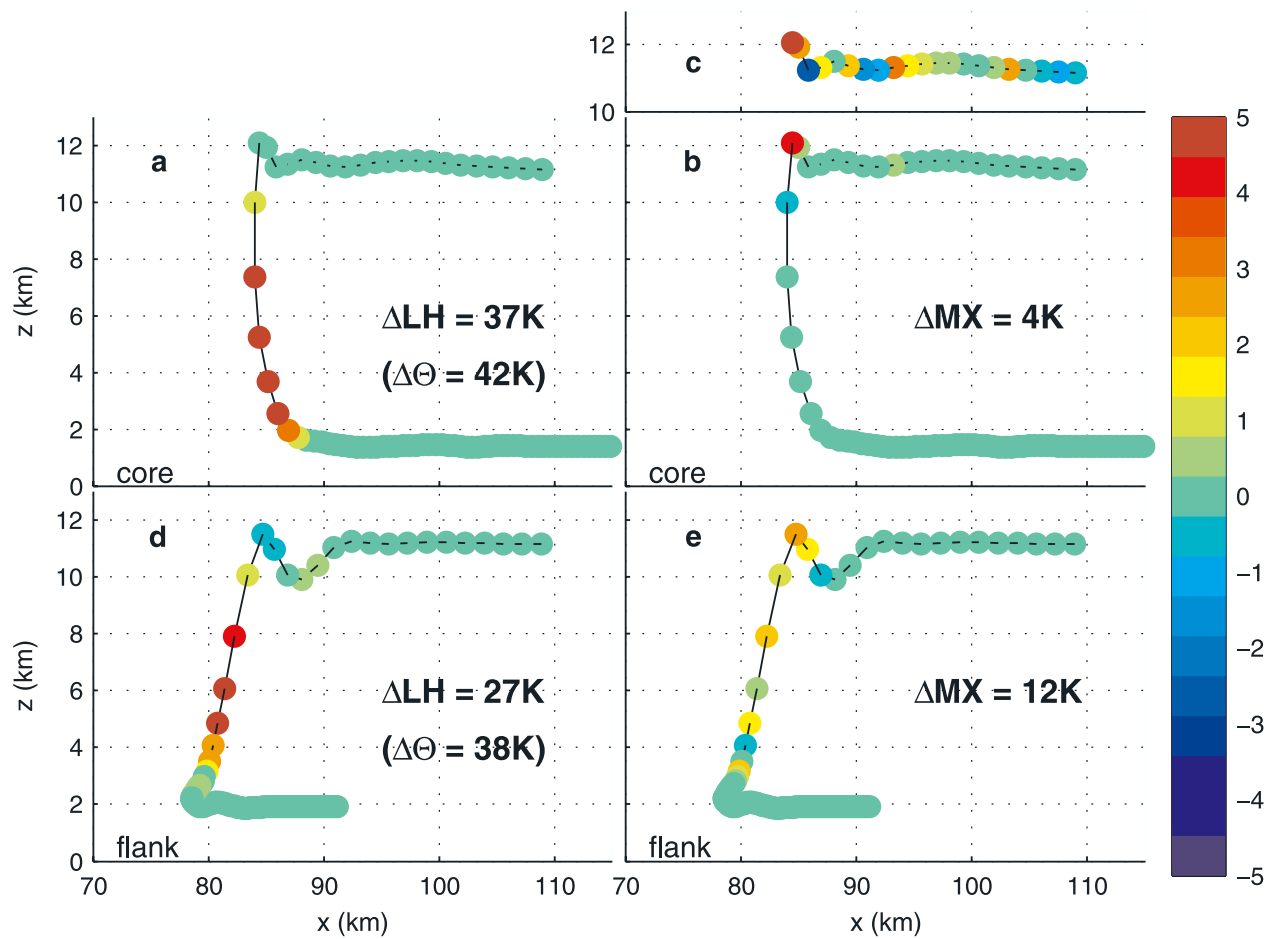

Figure 9. Projection onto the $x-z$ plane of trajectories rising from the boundary layer to the stratosphere $(\mathrm{a}-\mathrm{c})$ via the updraft core or ( $\mathrm{d}$ and $\mathrm{e}$ ) along the flank of the updraft. The cumulative potential temperature change over each 72-s interval due to various heat sources is denoted by the color of the dot. Figure 9c shows the same information as in the upper level portion of Figure $9 \mathrm{~b}$, except that the resolution in the color scale is 10 times finer, running from +0.5 to $-0.5 \mathrm{~K}$. The potential temperature changes due to latent heating are shown in Figures $9 \mathrm{a}$ and $9 \mathrm{~d}$; those due to mixing are plotted in Figures $9 \mathrm{~b}, 9 \mathrm{c}$, and $9 \mathrm{e}$. The total potential temperature change along the trajectory $(\Delta \Theta)$ as well as total changes to due latent heating $(\Delta \mathrm{LH})$ and mixing $(\Delta \mathrm{MX})$ are also indicated.

level air, and these weaker cells produce more outflow below the tropopause.

[32] Both the supercell and multicell storms had maximum updrafts of nearly $60 \mathrm{~ms}^{-1}$, but as shown in Figure 11, the supercell storm produced very strong vertical velocities throughout the mature stage of the storm while updrafts in the multicell storm only achieved such strength during the initial rapid growth stage. The oscillating maximum vertical velocity of the multicell storm (Figure 11, dashed line) is the signature of separate cells growing and dissipating, while in the supercell storm (Figure 11, solid line) one rotating updraft dominates for the entire first 2 hours. The updraft velocities in the supercell storm exceed $50 \mathrm{~ms}^{-1}$ continuously for more than 1.25 hours, while the multicell updrafts only exceed $50 \mathrm{~ms}^{-1}$ for a total of $\sim 20 \mathrm{~min}$ in two separate episodes.

[33] Figure 12 shows contours of vertical velocity in both the multicell and supercell simulations storms at $z=8.1 \mathrm{~km}$. The supercell simulation contains a multicell storm near $x=$ $70 \mathrm{~km}$ and $y=480 \mathrm{~km}$, but the southernmost cell in the supercell regime is clearly a supercell, as evidenced by the high values of vertical vorticity coincident with the updraft core. The supercell updraft is much stronger and larger in diameter than the multicell updrafts.

[34] Over the storm lifetime the differences in the magnitude of vertical velocities, cell lifetimes, and updraft diameters allow the supercell storm to transport nearly

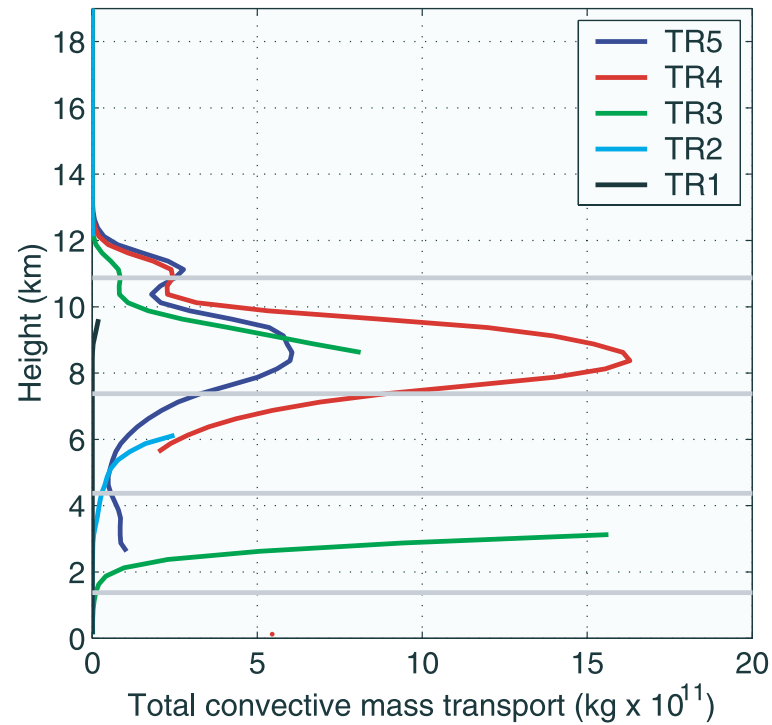

Figure 10. Total convective mass transport summed over entire domain at 10 hours into multicell simulation (same format as Figure $8 \mathrm{~b}$ ). The gray lines indicate the original locations of the tracer layers. 


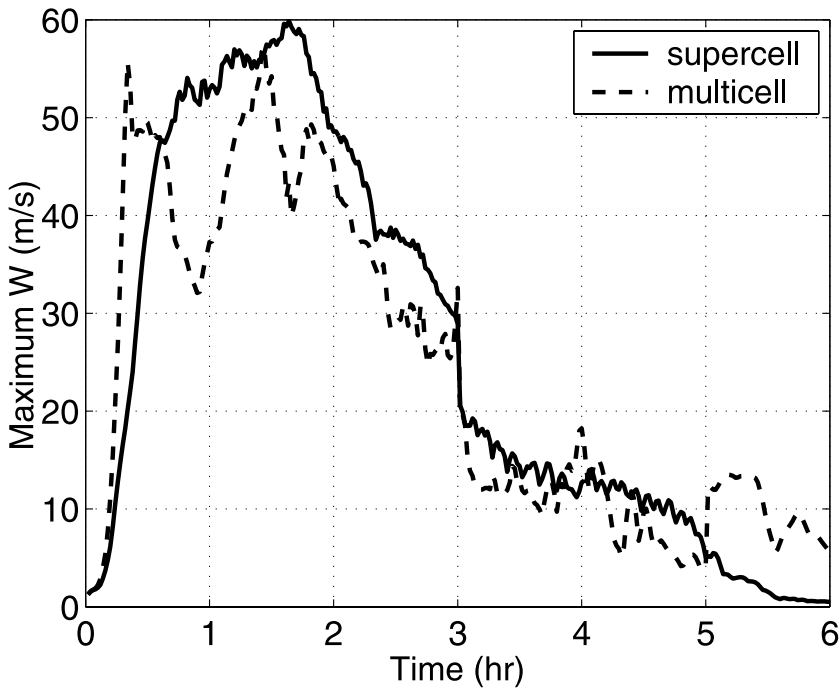

Figure 11. Maximum vertical velocity over the entire model domain for the typical supercell (solid line) and multicell (dashed line) simulations.

$100 \%$ more mass into the stratosphere than the multicell storm $\left(9.3 \times 10^{11} \mathrm{~kg}\right.$ of TR5 and $7.4 \times 10^{11} \mathrm{~kg}$ of TR4). These differences in updraft morphology all tend to produce less entrainment of midtropospheric air in through the flanks of the supercell updraft, a situation sometimes known as the "protected core" phenomenon [Hauf et al., 1995; Strom et al., 1999; Skamarock et al., 2000]. The higher rotation in the supercell updrafts may also contribute to the lower entrainment [Lilly, 1986]. The peaks in the relative vertical vorticity field shown in Figure $12 \mathrm{~b}$ are coincident with the location of the highest TR5 concentrations in the supercell case (not shown). While these results cannot be extrapolated to conclude that all supercell cases will produce more cross-tropopause transport than all multicell cases, it does appear that in cases with similar CAPE profiles and sufficient energy to produce upright updrafts the cells with supercell morphology will transport more material into the stratosphere.

\section{STEPS Storm}

[35] An exceptionally deep convective event occurred on 5 July 2000, at 2300 UT, during the Severe Thunderstorm Electrification and Precipitation Study (STEPS) campaign near the Kansas-Nebraska border [Miller and Weisman, 2002]. Overshooting cloud tops were observed to reach 18-19 km (M. Weisman, personal communication, 2001). With the undisturbed tropopause at $\sim 13.5 \mathrm{~km}$ and the LNB at $\sim 14.5 \mathrm{~km}$ this storm was a good candidate for significant troposphere-to-stratosphere transport.

[36] A simulation of this STEPS case was initialized with temperature, wind, and water vapor data that were composited from soundings taken from Goodland, Kansas, North Platte, Nebraska, Dodge City, Kansas, and Denver, Colorado. Goodland and North Platte were most relevant for the storm environment and were weighted most heavily in creating the composite (Figure 13). The composite sounding has a very high CAPE of $5034 \mathrm{~J} \mathrm{~kg}^{-1}$. The tracer profiles were modified from those shown in Figure 2 so that the boundary between TR 2 and TR 1 remains at the tropopause $(z=13.4 \mathrm{~km})$.

[37] The vertical velocity at $z=13.5 \mathrm{~km}$ reaches a storm maximum of $88 \mathrm{~ms}^{-1}$ with a maximum updraft height of $19 \mathrm{~km}$. The propagation speed of the simulated storm compared well with the propagation speed of the observed storm. Figure 14 shows cross sections of reflectivity of the observed storm (Figure 14a) and the simulated storm (Figure 14b). The reflectivity was calculated from model variables following Braun and Houze [1994]. It is difficult to match the exact cell maturity and orientation when comparing a simulated storm with a snapshot of the observed storm, but good agreement is shown in the updraft height, updraft width, and forward anvil size. The reflectivity shows the transport of hydrometeors and serves as a
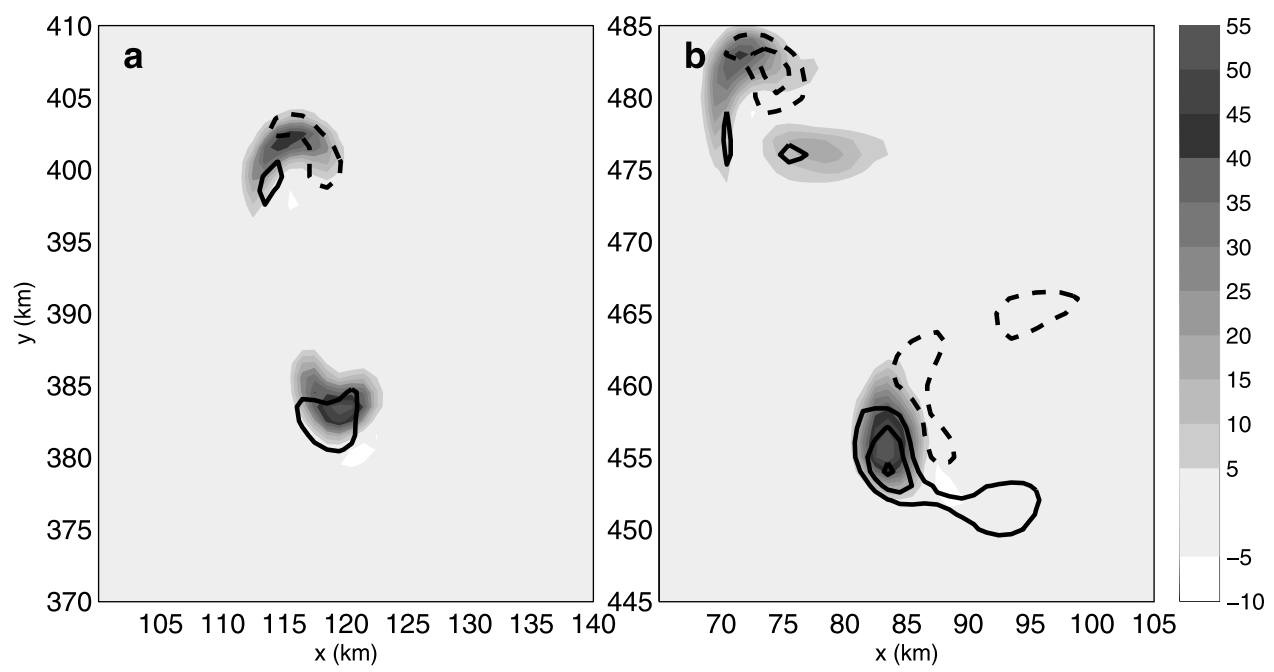

Figure 12. Shaded contours of vertical velocity for (a) the multicell simulation and (b) the typical supercell simulation at 1.5 hours. Black lines show contours of vertical relative vorticity; contour interval is $0.005 \mathrm{~s}^{-1}$. Dashed lines show negative contours. Horizontal slice is through updrafts at altitude of $8.1 \mathrm{~km}$. 

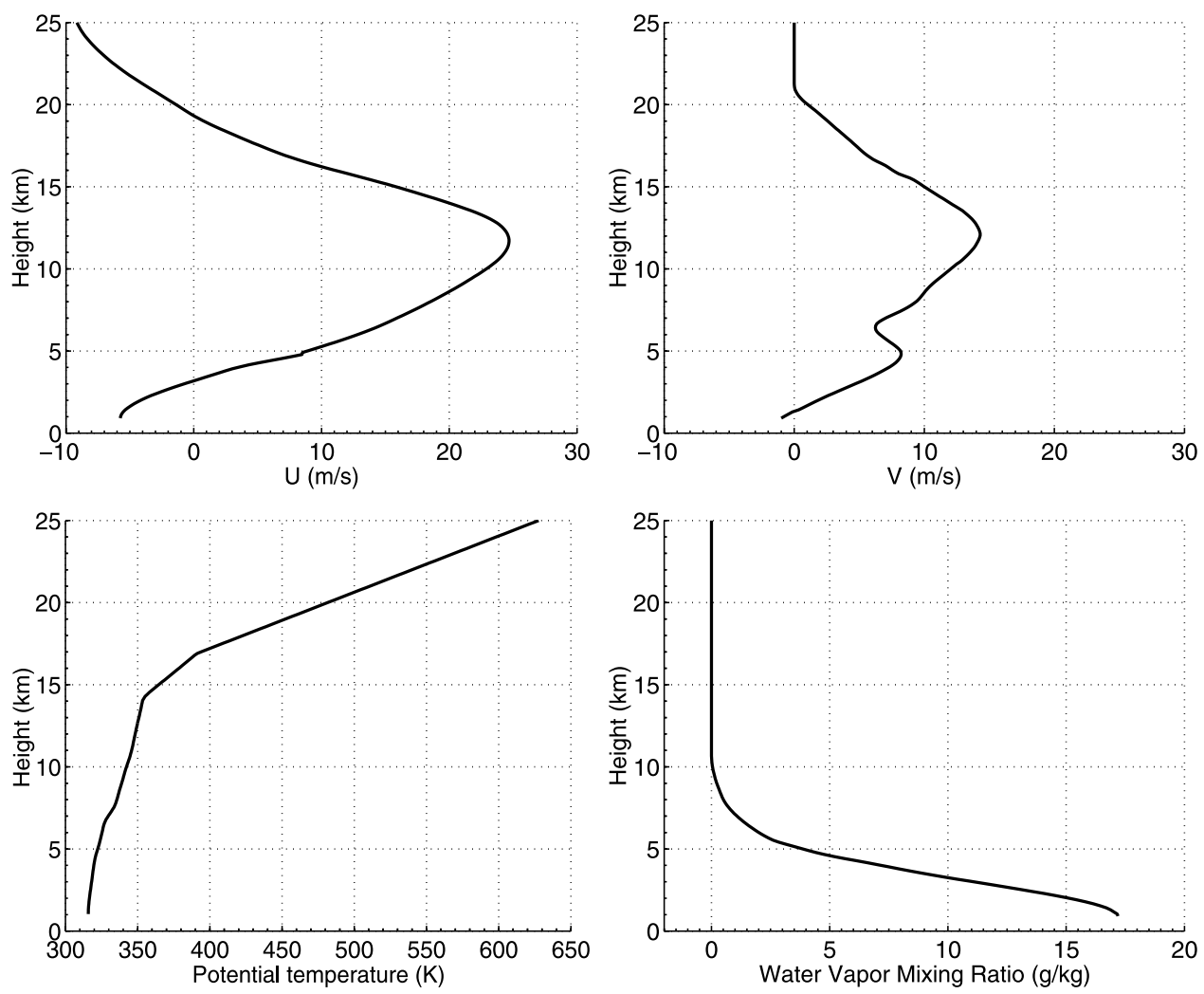

Figure 13. Composite sounding used for Severe Thunderstorm Electrification and Precipitation Study (STEPS) simulation.

proxy for tracer mass transport, giving us confidence in the simulated mass transport estimates. The reflectivity of the observed storm is somewhat lower than simulated, but again, this may be due to differences in the cell maturity. Our domain was not large enough to completely capture the strong wave activity caused by this deep storm after 6 hours of simulation, so we used the model state at 6 hours to calculate tracer transport. As in the supercell case the total convective transport above the tropopause is greatest for the boundary layer tracer; $2.2 \times 10^{12} \mathrm{~kg}$ of TR5 and $1.8 \times$
$10^{12} \mathrm{~kg}$ of TR 4 are injected into the stratosphere during the simulation. The STEPS storm produces more tracer transport than the typical supercell, confirming that the crosstropopause transport seen in the idealized case is not outside the bounds of reality.

\section{Chemical Transport Estimates}

[38] Validating the model results with available observations is difficult. In situ measurements are sparse, both
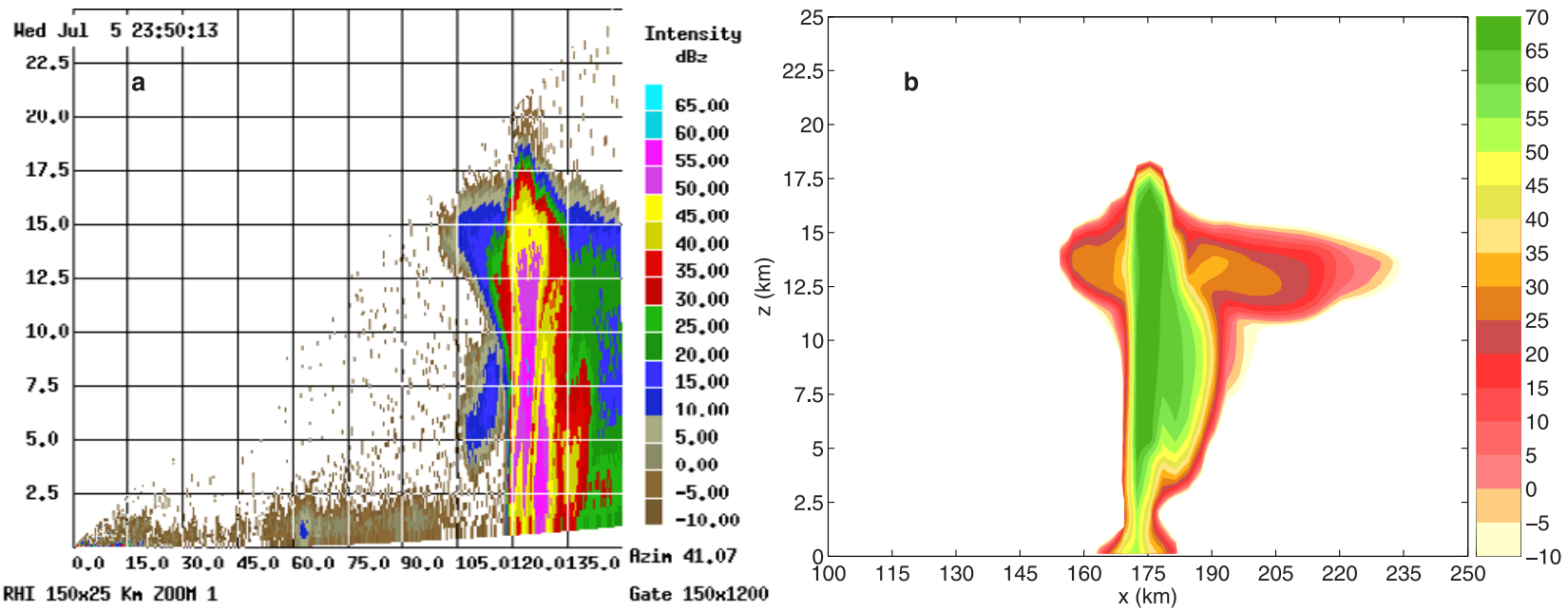

Figure 14. Comparison of reflectivity from (a) observed storm and (b) simulated storm. Observed storm reflectivity is measured by CHILL radar during STEPS campaign. Simulated storm is shown at 1 hour. 

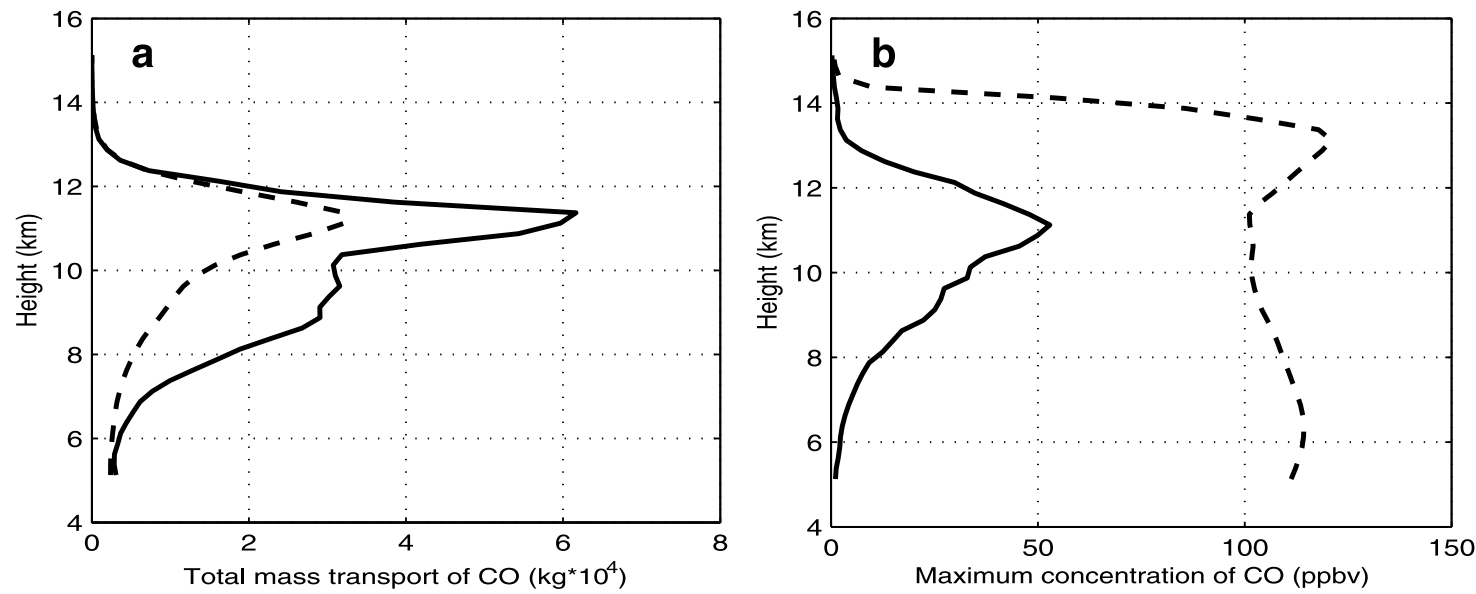

Figure 15. Estimated transport of $\mathrm{CO}$ at 2 hours (dashed line) and 10 hours (solid line) in the typical supercell storm. (a) Total mass of CO deposited at each level. (b) Maximum concentration of $\mathrm{CO}$ at each level.

temporally and spatially. In many of the field campaigns in which high-altitude tracer measurements were made the location of the perturbed tropopause is unknown so that it is not possible to estimate the irreversible transport into the stratosphere.

[39] Carbon monoxide ( $\mathrm{CO})$ is a frequently measured chemical with a boundary layer source and a lifetime long enough to be considered passive in convective transport. $\mathrm{CO}$ is not confined solely to the lower troposphere in typical soundings, but the concentration drops off rapidly above the boundary layer, and it has therefore been used as a proxy boundary layer tracer in previous studies. Suppose therefore that a field of $\mathrm{CO}$ was present with the same initial distribution as TR5 but having a typical midlatitude concentration of $135 \mathrm{ppb}$ throughout the lowest $1.5 \mathrm{~km}$. Figure 15 shows the mass transport (Figure 15a) and maximum concentration (Figure 15b) in the upper troposphere/lower stratosphere of CO that would develop under these assumptions at 2 and 10 hours in the typical supercell case. Authors such as Hauf et al. [1995], Poulida et al. [1996], and Strom et al. [1999] have observed anvil concentrations over $100 \mathrm{ppbv}$ of $\mathrm{CO}$, which are in reasonable agreement with the model results shown in Figure 15b. Notice that the level of maximum concentration descends $\sim 2 \mathrm{~km}$ (from 13 to $11 \mathrm{~km}$ ) after the convection dies out, demonstrating the usefulness of a study like this that can look at the long-term evolution of the tracer profile over the entire lifetime of the storm.

[40] Again, using a 135-ppbv concentration of $\mathrm{CO}$ in place of the TR5 tracer, one finds that the typical supercell simulation would have transported $2.4 \times 10^{5} \mathrm{~kg}$ of CO into the stratosphere over the lifetime of the storm. (A transport of $4.2 \times 10^{5} \mathrm{~kg}$ of $\mathrm{CO}$ was calculated by additionally replacing TR4 with $117 \mathrm{ppbv}$ and TR3 with 88 ppbv.) Stenchikov et al. [1996] estimated an injection of $0.05 \mathrm{Tg} \mathrm{yr}^{-1}$ of CO from MCCs as compared with the approximate $\mathrm{CO}$ production in the stratosphere of $100 \mathrm{Tg}$ $\mathrm{yr}^{-1}$. Our simulations suggest that isolated storms could transport tracer amounts comparable to the estimated transport in MCCs; to reach the level of $0.05 \mathrm{Tg} \mathrm{yr}^{-1}$ of $\mathrm{CO}$ would take only 200 typical supercell storms. To reach the level of $100 \mathrm{Tg} \mathrm{yr}^{-1}$, however, would take $4 \times 10^{5}$ typical supercell storms. This suggests that while $\mathrm{CO}$ concentrations might be enhanced locally in the region overlying the storm, convective transport is not a significant source of $\mathrm{CO}$ in the stratosphere.

[41] However, convection may still play a significant role in the transport of other trace gases between the boundary layer and the stratosphere. Many chemically reactive trace gases have atmospheric lifetimes on the order of hours to weeks so that rapid convective transport might play a crucial role in defining the global distributions and chemical effects of these gases. Halogen compounds, significant players in stratospheric ozone destruction, are one family of such gases. For example, bromoform $\left(\mathrm{CHBr}_{3}\right)$, a potentially significant source of bromine, has been shown to exist in the midlatitude stratosphere despite its short tropospheric lifetime [Sturges et al., 2000] possibly because of convective transport.

\section{Summary and Conclusions}

[42] A three-dimensional cloud-resolving model was used to investigate passive tracer transport from the lower troposphere to the stratosphere in midlatitude convection. This study evaluates the cross-tropopause transport using a dynamic tropopause definition. The long-term evolution of the tracer plume was verified by suppressing the convection at 1.5 hours and then simulating the tracer plume to 10 hours. Air parcels containing boundary layer tracers were able to penetrate the stable stratosphere, and diabatic processes, specifically latent heating and/or turbulent mixing, increased the parcel potential temperature sufficiently to make the parcel stable at stratospheric altitudes.

[43] Three different convective storms were simulated: two prototypical idealized cases, a supercell and a multicell which develop in identical large-scale environments except for the low-level wind shear, and one observed supercell, the STEPS storm. The irreversible transport into the stratosphere of boundary layer tracer (TR5) and tracer from the next level up (TR4) is plotted as a function of time in Figure 16 for all three storms. The STEPS storm produced slightly more transport than the idealized supercell. The transport by the multicell was roughly half that of the 

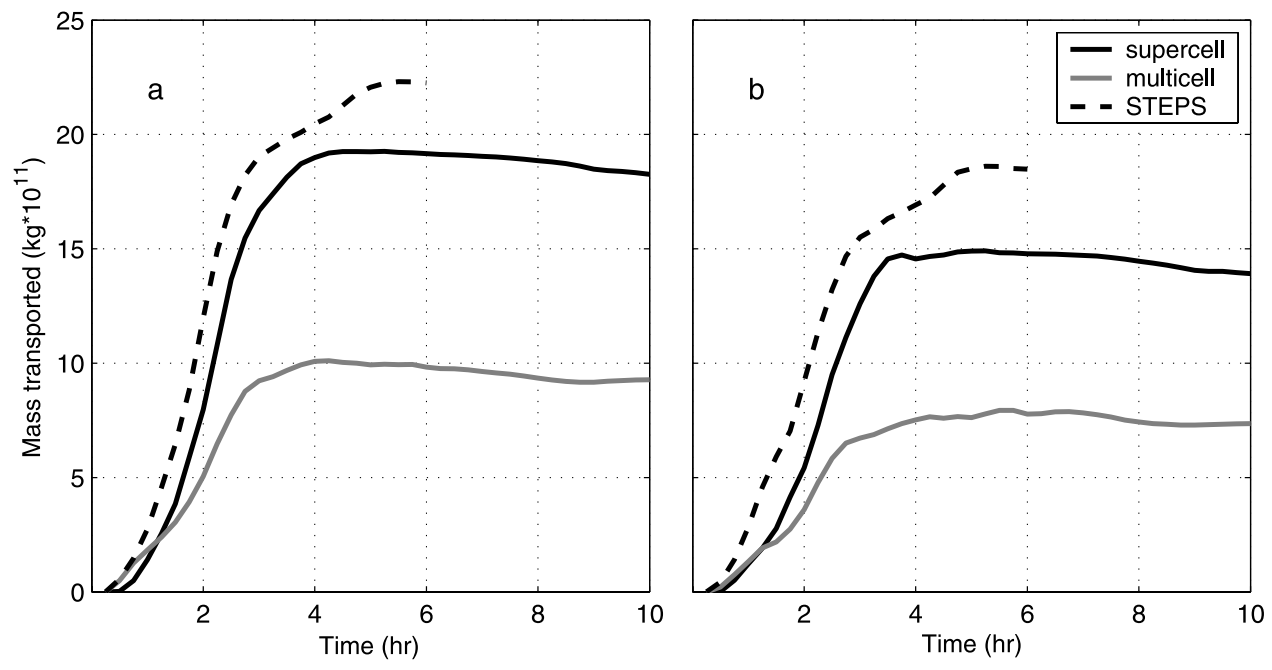

Figure 16. Total amount of (a) TR5 and (b) TR4 transported into the stratosphere for each simulation.

idealized supercell because the updrafts in the supercell were larger in diameter and sustained higher vertical velocities for longer times. Although the source region for TR5 was only one third the depth of that of TR4 (initially occupying the region $1 \leq z \leq 4 \mathrm{~km}$ ), more TR5 is carried into the stratosphere by all three storms. The boundary layer tracer ascended in the updraft cores, whereas TR4 experienced weaker ascent on the flanks of the updrafts.

[44] Very little stratospheric air was transported deep into the troposphere in these simulations. Previous authors have reported greater downward displacement of the stratospheric air at anvil edge [e.g., Stenchikov et al., 1996]. These studies appear to have exclusively focused on squall lines. It is reasonable to expect a larger downward deflection of stratospheric air associated with mass compensation in a two-dimensional structure like a squall line where stratospheric air displaced by the anvil is constrained to circulate in two dimensions instead of a three-dimensional shield anvil where air can descend in all directions.

[45] Convective transport into the stratosphere is small compared to transport produced by larger-scale systems, but because of its efficiency in transporting boundary layer tracers, deep convection may be a significant source of halogen compounds and other volatile tropospheric tracers in the lowermost stratosphere. More work needs to be done to capture the effect of storm and environmental details, such as the level of neutral buoyancy and lower-stratospheric shear, on deposition profiles in the stratosphere.

[46] Acknowledgments. During the revisions of the final draft of this paper, Jim had a stroke on one of his daily jogs. He passed away one week later. We dedicate this paper to the memory of a scientific giant and our friend, Jim Holton. This work was supported by the National Science Foundation Division of Atmospheric Sciences, NSF grants ATM-0225441 and ATM-997924. The authors would like to thank Joan Alexander, Lyatt Jaegle, and two anonymous reviewers for their helpful comments. The authors also thank Morris Weisman for bringing the strong STEPS case to our attention. The reflectivity cross section in Figure 14a was provided by the NSF-funded CSU-CHILL national radar facility.

\section{References}

Braun, S. A., and R. A. Houze Jr. (1994), The transition zone and secondary maximum of radar reflectivity behind a midlatitude squall line: Results retrieved from doppler radar data, J. Atmos. Sci., 51, 2733-2755.
Dickerson, R. R. (1987), Thunderstorms: An important mechanism in the transport of air pollutants, Science, 235, 460-465.

Durran, D. R., and J. B. Klemp (1983), A compressible model for the simulation of moist mountain waves, Mon. Weather Rev., 111, 23412361.

Hauf, T., P. Schulte, R. Alheit, and H. Schlager (1995), Rapid vertical transport by an isolated midlatitude thunderstorm, J. Geophys. Res., $100,22,957-22,970$

Haynes, P. H. (2002), Turbulence and mixing, in Encyclopedia of Atmospheric Sciences, pp. 2446-2450, Elsevier, New York.

Hegglin, M. I., et al. (2004), Tracing troposphere-to-stratosphere transport above a mid-latitude deep convective system, Atmos. Chem. Phys. Discuss., 4, 169-206.

Hintsa, E. J., et al. (1998), Troposphere-to-stratosphere transport in the lowermost stratosphere from measurements of $\mathrm{H}_{2} \mathrm{O}, \mathrm{CO}_{2}, \mathrm{~N}_{2} \mathrm{O}$ and $\mathrm{O}_{3}$, Geophys. Res. Lett., 25, 2655-2658.

Holton, J. R., P. H. Haynes, M. E. McIntyre, A. R. Douglass, R. B. Rood, and L. Pfister (1995), Stratospheric-tropospheric exchange, Rev. Geophys., 33, 403-439.

Lane, T. P., R. D. Sharman, T. L. Clark, and H.-M. Hsu (2003), An investigation of turbulence generation mechanisms above deep convection, J. Atmos. Sci., 60, 1297-1321.

LeVeque, R. J. (1996), High-resolution conservative algorithms for advection in incompressible flow, SIAM J. Numer. Anal., 33, $627-665$.

Lilly, D. K. (1986), The structure, energetics and propagation of rotating convective storms. Part II: Helicity and storm stabilization, J. Atmos. Sci., 43, $126-140$

Lu, R., C. Lin, R. Turco, and A. Arakawa (2000), Cumulus transport of chemical tracers 1) cloud-resolving model simulations, J. Geophys. Res., $105,10,001-10,021$.

Miller, L. J., and M. L. Weisman (2002), Comparison of radar-observed and WRF-modeled structures of two STEPS storms, paper presented at $21 \mathrm{st}$ Conference on Severe Local Storms, Am. Meteorol. Soc., San Antonio, Tex.

Park, S. K., and K. K. Droegemeier (2000), Sensitivity analysis of a 3D convective storm: Implications for variational data assimilation and forecast error, Mon. Weather Rev, 128, 140-159.

Piani, C., D. Durran, M. Alexander, and J. R. Holton (2000), A numerical study of three-dimensional gravity waves triggered by deep tropical convection and their role in the dynamics of the QBO, J. Atmos. Sci., 57, $3689-3702$

Poulida, O., R. R. Dickerson, and A. Heymsfield (1996), Stratospheretroposphere exchange in a midlatitude mesoscale convective complex: 1. Observations, J. Geophys. Res., 101, 6823-6839.

Scala, J. R., et al. (1990), Cloud draft structure and trace gas transport, J. Geophys. Res., 95, 17,015-17,030.

Sigmond, M., J. Meloen, and P. C. Siegmund (2000), Stratosphere-troposphere exchange in an extratropical cyclone, calculated with a Lagrangian method, Ann. Geophys., 18, 573-582.

Skamarock, W. C., J. G. Powers, M. Barth, J. E. Dye, T. Matejka, D. Bartels, K. Baumann, J. Stith, D. D. Parrish, and G. Hubler (2000), Numerical simulations of the July 10 Stratospheric-Tropospheric Experiment: Radiation, Aerosols, and Ozone/Deep Convection Experiment convec- 
tive system-Kinematics and transport, J. Geophys. Res., 105, 19,97319,990 .

Sprenger, M., and H. Wernli (2003), A Northern Hemispheric climatology of cross-tropopause exchange for the ERA15 time period (1979-1993), J. Geophys. Res., 108(D12), 8521, doi:10.1029/ 2002JD002636.

Stenchikov, G., R. Dickerson, K. Pickering, W. Ellis, B. Doddridge, S. Kondragunta, O. Poulida, J. Scala, and W. Tao (1996), Stratospheretroposphere exchange in a midlatitude mesoscale convective complex: 2. Numerical simulations, J. Geophys. Res., 101, 6837-6851.

Strom, J., H. Fischer, J. Lelieveld, and F. Schroder (1999), In situ measurements of microphysical properties and tracer gases in two cumulonimbus anvils over western Europe, J. Geophys. Res., 104, $12,221-12,226$

Sturges, W. T., D. E. Oram, L. J. Carpenter, and S. A. Penkett (2000), Bromoform as a source of stratospheric bromine, Geophys. Res. Lett., 27(14), 2081-2084.

Tao, W.-K., and J. Simpson (1993), Goddard Cumulus Ensemble Model. Part I: Model description, Terr. Atmos. Oceanic Sci., 4, 35-72.
Wang, C., and J. Chang (1993), A three-dimensional numerical model of cloud dynamics, microphysics, and chemistry: 3. Redistribution of pollutants, J. Geophys. Res., 98, 16,787-16,798.

Wang, P. K. (2003), Moisture plumes above thunderstorm anvils and their contributions to cross-tropopause transport of water vapor in midlatitudes, J. Geophys. Res., 108, 4194, doi:10.1029/2002JD002581.

Weisman, M. L., and J. Klemp (1982), The dependence of numerically simulated convective storms on vertical wind shear and buoyancy, Mon. Weather Rev., 110, 504-520.

Weisman, M. L., and J. Klemp (1986), Characteristics of isolated convective storms, in Mesoscale Meterology and Forecasting, pp. 331-358, Am. Meteorol. Soc., Boston, Mass.

D. R. Durran, Department of Atmospheric Sciences, University of Washington, Box 351640, Seattle, WA 98195, USA.

G. L. Mullendore, Department of Atmospheric and Oceanic Sciences, 7127 Math Sciences Building, 405 Hilgard Avenue, Los Angeles, CA 90095-1565, USA. (gretchen@atmos.ucla.edu) 